\title{
Three Non-allelic Genes for Pisatin Demethylation in the Fungus Nectria haematococca
}

\author{
By H. CORBY KISTLER† AND HANS D. VANETTEN* \\ Department of Plant Pathology, Cornell University, Ithaca, NY 14853, USA
}

(Received 4 January 1984; retised 23 May 1984)

\begin{abstract}
Isolates of the plant pathogenic fungus Nectria haematococca can demethylate pisatin, an isoflavonoid phytoalexin produced by pea. Previous evidence has shown that pisatin demethylase is a cytochrome P-450 monooxygenase. In culture some isolates can be induced to demethylate pisatin at a high rate by pretreatment with the substrate, while others demethylate pisatin more slowly, regardless of pretreatment. Results from the present study indicate that in two naturally occurring isolates these pisatin demethylating phenotypes are controlled by genes at three loci. The phenotype with high pisatin demethylating activity is conferred by an allele at locus pda-1. Alleles at each of two other loci ( $p d a-2, p d a-3)$ confer low pisatin demethylating activity. Only isolates with negative alleles at all three loci lack pisatin demethylase activity altogether. Locus $p d a-l$ appears to be linked to a gene determining female fertility $(\mathrm{fem})$ in this fungus.
\end{abstract}

\section{INTRODUCTION}

Like many other plants, the garden pea (Pisum saticum L.) can produce and accumulate antimicrobial substances (phytoalexins) when challenged by micro-organisms. Phytoalexins have been suggested to be the basis for active resistance to plant disease in many instances (Cruickshank, 1980). The major phytoalexin of pea is the isoflavonoid compound pisatin (Perrin \& Bottomley, 1962).

Many isolates of the fungus Nectria haematococca Berk. and Br., mating population (MP) VI (imperfect form: Fusarium solani) are highly virulent pathogens of pea (VanEtten, 1978; VanEtten et al., 1980). In response to a challenge by either highly virulent or essentially avirulent isolates of $N$. haematococca, pea plants accumulate high concentrations of pisatin (Tegtmeier \& VanEtten, $1982 b$ ). To date, all tested isolates of $N$. haematococca that are highly or moderately virulent to pea have been found to be capable of demethylating pisatin to the corresponding phenol, DMDP (Tegtmeier \& VanEtten, 1982b; Van Etten et al., 1980), which is less toxic to the fungus than pisatin (VanEtten et al., 1975, 1982). Some isolates of the fungus lack the ability to demethylate pisatin, and all of these are low in virulence (Tegtmeier \& VanEtten, 1982b; VanEtten et al., 1980). The enzyme pisatin demethylase, studied in one demethylating isolate, is a microsomal cytochrome P-450 monooxygenase (Desjardins et al., 1984; Matthews \& VanEtten, 1983). This monooxygenase may thus be required for fungal virulence to pea (VanEtten, 1982).

Previous random ascospore and tetrad analysis of $N$. haematococca suggested that alleles at any one of at least two loci may be sufficient to confer a pisatin demethylating phenotype

+ Present address: Department of Plant Pathology, 1630 Linden Drive, University of Wisconsin, Madison, W1 53706, USA.

Abbresiation: DMDP, 3,6a-dihydroxy-8,9-methylenedioxypterocarpan. 
(Tegtmeier \& VanEtten, 1982b). Subsequent work has described different regulatory phenotypes for pisatin demethylating isolates (VanEtten \& Matthews, 1984). Some isolates demethylate pisatin only at a low rate ('non-inducible' isolates, designated PDA") while others show much greater activity when pretreated with substrate ('inducible' isolates, designated PDA $^{i}$ ). The purpose of this investigation was to examine, by random ascospore and tetrad analysis, the genetic basis for the PDA $^{i}$ and PDA $^{n}$ pisatin demethylating phenotypes.

\section{METHODS}

Fungal isolates. Nectria haematococca MP VI is a heterothallic ascomycete that forms asci in perithecia. Several phenotypic traits segregate in normal Mendelian ratios in this organism, indicating that standard meiotic genetic analysis is possible (Defago et al., 1983; Holenstein \& Defago, 1983; Tegtmeier \& VanEtten, 1982a).

Mating isolates used in this study are described in Table 1 . Isolate designations beginning with the letter $T$ are field isolates obtained from natural habitats (VanEtten, 1978; VanEtten et al., 1980). Isolates obtained as ascospores from crosses are given two or three numbers, depending on whether they are random or tetrad ascospores, respectively. The first of these numbers designates a particular cross. The second number, for a random ascospore, designates a particular ascospore from that cross. For tetrads, the second number designates a particular ascus, whereas the third number designates an ascospore of that ascus. For example, 77-5 and 77-10-2 are random ascospore 5 , and ascospore 2 from ascus 10 , respectively, of cross 77 .

\section{Table 1. Parent isolates}

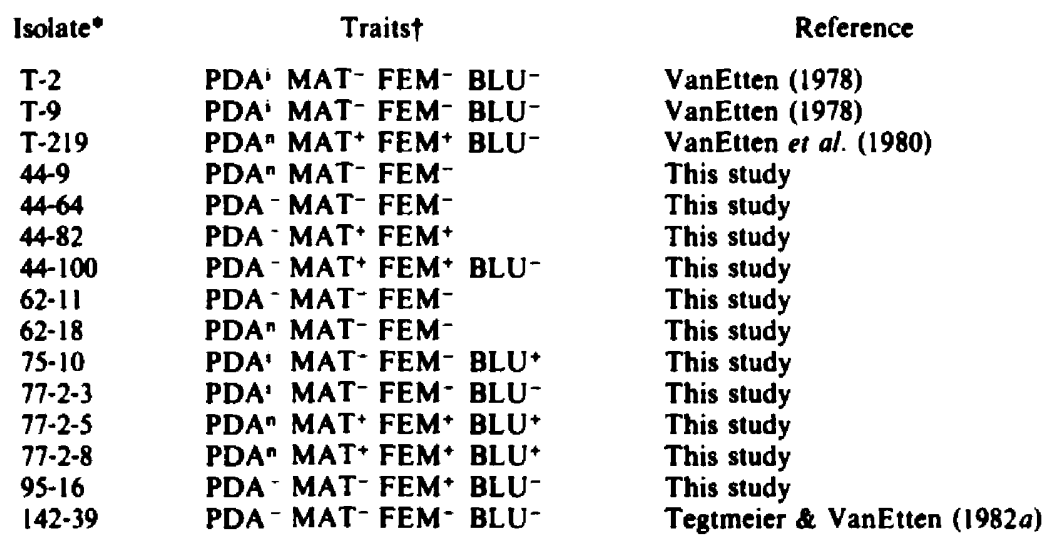

- T-2 and T-9 are field isolates obtained from diseased peas and T-219 is a field isolate obtained from soil. Other isolates are single ascospore isolations.

t See text for description of phenotypes.

All isolates were maintained on V-8 juice agar (medium 29 ; Stevens, 1974) under fluorescent lighting at $20^{\circ} \mathrm{C}$. Techniques for crossing and ascospore isolation have been described previously (Tegtmeier \& VanEtten, $1982 a$; VanEtten, 1978). Crosses between isolates were made by spreading spores of a female fertile (FEM ${ }^{*}$ ) isolate on $\mathrm{V}$ 8 juice agar medium, and allowing mycelium to develop, at $20^{\circ} \mathrm{C}$, for 6 to $14 \mathrm{~d}$. After this period, spores from 6 to $14 \mathrm{~d}$ cultures of a female sterile (FEM ${ }^{-}$) isolate of opposite mating type were spread on the FEM ${ }^{+}$mycelium in a small volume of sterile distilled water. Excess water was poured off and the fertilized cultures were incubated under continuous fluorescent lighting. Ascospores from developing perithecia were isolated 2 to 4 weeks after fertilization.

Asci of $N$. haematococca contain a maximum of eight ascospores, representing mitotic pairs of the four meiotic products. Frequently, however, fertile matings resulted in many asci with fewer than the maximum number of ascospores. For tetrad analysis it was often necessary to isolate asci with only six or seven ascospores. If segregation of other markers (see below) in asci with less than eight spores indicated that the four meiotic products were represented, these tetrads were used for genetic analysis of pisatin demethylase phenotypes and the ratios are reported as if all eight spores were present.

Markers followed in crosses were mating type (MAT), female fertility (FEM), and pisatin demethylase phenotype (PDA). In later crosses, blue pigmentation of mycelium (BLU) was used as an additional marker. Blue pigmentation of the normally white mycelium develops on V-8 juice agar medium, is light-dependent, and appears to be under the control of two linked genes (Kistler, 1983). 
Isoflavonoids. Pisatin and its demethylated product, DMDP, were isolated as described previously (VanEtten et al., 1975). Pisatin specifically labelled with ${ }^{14} \mathrm{C}$ at the $3-O$-methyl position ([ $\left.{ }^{14} \mathrm{C}\right]$ pisatin) was prepared by methods published previously (VanEtten et al., 1980). Pisatin and DMDP concentrations were determined photometrically using the molar extinction coefficients of $\log \varepsilon=3.86$ at $309 \mathrm{~nm}$ (Perrin \& Bottomley, 1962), and $\log \varepsilon=3.88$ at $309 \mathrm{~nm}$ (VanEtten et al.. 1975), respectively.

Defining and determining pisatin demethylase phenotypes. (i) Method 1 . Conidia (about $10^{\circ} \mathrm{ml}^{-1}$ ) of fungal isolates were suspended in $40 \mathrm{ml}$ autoclaved succinate medium (VanEtten et al., 1980) contained in $125 \mathrm{ml}$ Erlenmeyer flasks. Cultures were incubated on a reciprocal shaker (110 strokes $\mathrm{min}^{-1}$ ) at $27^{\circ} \mathrm{C}$ for approximately $72 \mathrm{~h}$. The resulting mycelium was then filtered through cotton cloth and washed with $50 \mathrm{ml}$ distilled water. Mycelium was resuspended in potassium phosphate buffer $(50 \mathrm{~mm}, \mathrm{pH} 6.5)$ at a density of $30 \mathrm{mg}$ fresh weight mycelium $\mathrm{ml}^{-1}$. Samples of $5 \mathrm{ml}$ of the resulting suspensions were placed in $25 \mathrm{ml}$ Erlenmeyer flasks. Pisatin (not radiolabelled) was then added to each culture in $25 \mu \mathrm{l}$ DMSO solvent to give a final pisatin concentration of $31 \mu \mathrm{g} \mathrm{ml}^{-1}(0 \cdot 1 \mathrm{mM})$. Cultures were incubated on a reciprocal shaker $\left(110\right.$ strokes $\left.\min ^{-1}\right)$ at $20^{\circ} \mathrm{C}$ for 6 to $8 \mathrm{~h}$. After this period of substrate pretreatment, $31 \mu \mathrm{g}\left[{ }^{1+} \mathrm{C}\right]$ pisatin $\left(1.1 \times 10^{-4} \mathrm{~d} . \mathrm{p} . \mathrm{m}\right.$.) was added to each $\mathrm{ml}$ of culture, again in a total volume of $25 \mu \mathrm{l}$ DMSO. Samples $(0.75 \mathrm{ml})$ were removed at four $5 \mathrm{~min}$ intervals, and placed immediately into $4.5 \mathrm{ml}$ of $0.5 \% \mathrm{PPO} /$ toluene scintillation fluid. Most $\left[3-O-\right.$ methy $\left./{ }^{1+} \mathrm{C}\right]$ pisatin in the resulting biphasic mixtures is partitioned into the upper toluene phase, whereas ${ }^{1+} \mathrm{C}$ derived from demethylated pisatin either remains in the lower aqueous phase and is not detected or is lost as ${ }^{1+} \mathrm{CO}_{2}$ (VanEtten $e t$ al., 1980). ${ }^{14} \mathrm{C}$ content was measured on a Beckman LS355 scintillation spectrometer. The amounts of labelled pisatin in the four samples, plotted against time, were subjected to linear regression analysis. The slope of the regression line was converted to a corresponding rate of pisatin demethylation expressed in pmol $\min ^{-1}\left(\mathrm{mg}\right.$ fresh wt mycelium) ${ }^{-1}$. Isolates with detectable demethylation rates over this time interval were scored as having the high activity, inducible pisatin demethylase

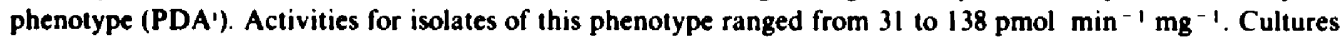
with demethylation rates less than the minimum detectable by this assay $\left(<11 \mathrm{pmol} \mathrm{min}^{-1} \mathrm{mg}^{-1}\right)$ were judged to have either low activity (PDA ${ }^{n}$ ) or non-demethylating (PDA ${ }^{-}$) phenotypes.

To distinguish PDA $^{n}$ from PDA ${ }^{-}$isolates, the cultures described above were incubated further on a rotary shaker ( 110 r.p.m.) at ambient temperature for approximately $48 \mathrm{~h}$ after the addition of $\left[{ }^{1+} \mathrm{C}\right]$ pisatin. At this time a further $0.75 \mathrm{ml}$ sample was removed, added to the toluene based scintillation fluid and counted. Cultures retaining $>90 \%$ of the added ${ }^{4} \mathrm{C}$ in the toluene layer were judged to be of the non-demethylating (PDA ${ }^{-}$) phenotype. Cultures retaining less than $50 \%$ of the ${ }^{1+} \mathrm{C}$ in the toluene layer at $48 \mathrm{~h}$, and not having the PDA' phenotype, were scored as low-activity, pisatin demethylating isolates $\left(\mathrm{PDA}^{n}\right)$. Occasionally cultures failed to fall within the defined limits of these phenotypic classes. Upon re-testing by this method, or by method 2 or 3, the phenotype of these isolates became apparent (Kistler, 1983).

(ii) Method 2. Rates of pisatin demethylation were established for selected low activity, PDA ${ }^{n}$ isolates by the following procedure. Cultures were grown in succinate medium, filtered, and resuspended in buffer as described for Method 1. [ $\left.{ }^{+} \mathrm{C}\right]$ Pisatin was then added directly to these cultures in $25 \mu$ ] DMSO (final pisatin concentration $31 \mu \mathrm{g} \mathrm{ml} \mathbf{~}^{-1} ; 1.1 \times 10^{4} \mathrm{~d}$.p.m. $\left.\mathrm{ml}^{-1}\right)$. Samples $(0.75 \mathrm{ml})$ were then removed from cultures immediately $(<5 \mathrm{~min})$ and at three or four intervals throughout the $72 \mathrm{~h}$ period following the addition of pisatin. Samples were placed in scintillation fluid and counted. Rates of pisatin demethylation were calculated from regression lines of these data.

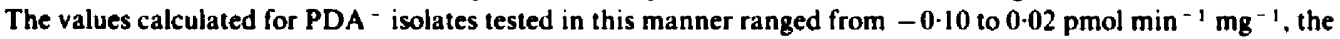
negative values apparently arising from loss of water from cultures by evaporation. The apparent rate of a control $\mathrm{PDA}^{-}$culture was therefore subtracted from calculated rates for PDA ${ }^{n}$ isolates to correct for this effect. Rates for PDA $^{n}$ cultures determined in this manner ranged from 0.22 to $1.02 \mathrm{pmol} \mathrm{min}^{-1} \mathrm{mg}^{-1}$

(iii) Method 3. Because demethylase activities for PDA ${ }^{n}$ isolates were sometimes very low, and at times difficult to detect by methods $L$ or 2 , an additional method for measuring demethylating ability over longer periods. modified from a previously described technique (Tegtmeier \& VanEtten, 1982b), was used. Mycelium was grown from spores for $2 \mathrm{~d}$ on Petri plates containing a glucose/peptone agar medium (M-2, VanEtten, 1973). A disc $4 \mathrm{~mm}$ in diameter was cut from each culture with a cork borer and placed on a $7 \times 35 \mathrm{~mm}$ Petri plate containing $\mathrm{I} \mathrm{ml}$ M-2 medium supplemented with $161 \mu \mathrm{g}\left[{ }^{1+} \mathrm{C}\right]$ pisatin $\left(1 \cdot 1 \times 10^{4} \mathrm{~d} . \mathrm{p} . \mathrm{m}\right.$.). Mycelium was allowed to cover the plate and after approximately 2 weeks the agar was scraped from the plates and placed in the scintillation fluid described above. PDA- cultures retained between 93 and $106^{\circ}$ of the added toluene-soluble radioactivity, whereas PDA $^{n}$ cultures retained less than $22^{\circ}$ 。

Chemical confirmation of pisatin demethylation in parent isolates. To test whether retention or loss of toluenepartitioning ${ }^{1+C}$ corresponded to retention or loss of pisatin from cultures, the parent isolates of most crosses discussed in this paper (T-2, T-129, and 44-100) were prepared for phenotype determination as described for Method 1. However, in this case. $1.0 \mathrm{ml}$ samples were removed from cultures $3 \mathrm{~min}, 3 \mathrm{~h}$, and $48 \mathrm{~h}$ after addition of $\left[{ }^{1+} \mathrm{C}\right]$ pisatin, and extracted with $4.5 \mathrm{ml}$ toluene. The toluene phase was evaporated under reduced pressure, and the resulting residues were spotted on silica gel thin layer chromatography plates with fluorescent indicator (Whatman LKSF, $0 \cdot 25 \mathrm{~mm}$ ), in parallel with unlabelled pisatin and DMDP standards. The plates were developed 
in $\mathrm{CHCl}_{3} / \mathrm{CH}_{3} \mathrm{OH}(25: 1 \mathrm{v} / \mathrm{v})$, dried, and placed next to a sheet of X-ray film (Kodak X-OMAT AR) for $28 \mathrm{~d}$. The resulting autoradiograms indicated that for the $\mathrm{PDA}^{-}$isolate $(44-100)$ all the detected toluene-soluble radioactivity after $48 \mathrm{~h}$ was contained in a single spot corresponding to the pisatin standard. For both PDA' (T-2) and PDA" (T-219) isolates, loss of radioactivity corresponded to loss of a fluorescence-quenching spot co-migrating with the pisatin standard. Both T-2 and T-219 cultures accumulated a non-radioactive fluorescence-quenching substance that co-migrated with the DMDP standard.

\section{RESULTS}

\section{Assays for pisatin demethylase phenotypes}

Fig. 1 shows representative assays for pisatin demethylation as determined by Method 1. Only the inducible, high activity PDA $^{i}$ isolates showed detectable demethylase activity during the 20 min time course, after 6 to $8 \mathrm{~h}$ pretreatment with substrate. The low activity PDA ${ }^{n}$ and nondemethylating PDA - isolates were distinguished by the amount of $\left[{ }^{14} \mathrm{C}\right]$ pisatin remaining in culture after $48 \mathrm{~h}$.

Method 2 permitted assessment of the demethylation rate for the PDA ${ }^{\mathrm{n}}$ isolates (Fig. 2).

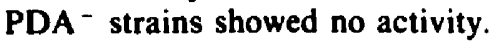

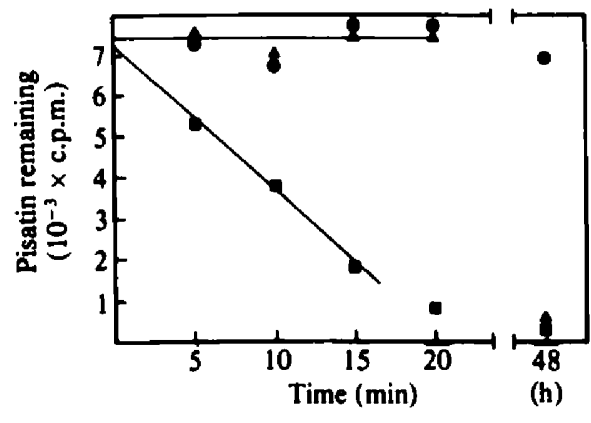

Fig. 1

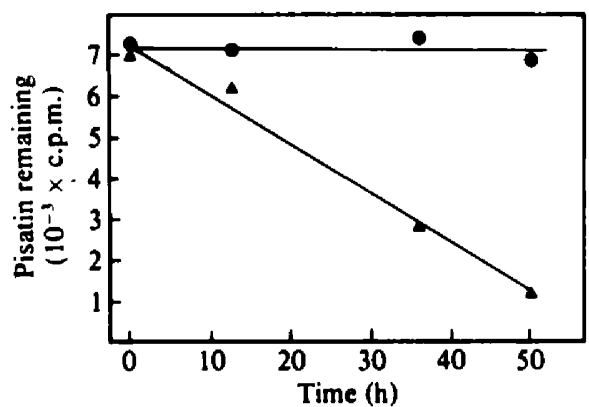

Fig. 2

Fig. 1. An illustration of the different pisatin demethylase phenotypes as determined by Method 1. Sample size was $0.75 \mathrm{ml}$. Isolates shown are: $\square, \mathrm{PDA}^{\prime} ; \triangle, \mathrm{PDA}^{\mathrm{n}}$;, $\mathrm{PDA}^{-}$.

Fig. 2. An illustration of the differences between $\operatorname{PDA}^{n}(A)$ and $\operatorname{PDA}^{-}(O)$ phenotypes when assayed by Method 2. Sample size was $0.75 \mathrm{ml}$.

\section{Inheritance of PDA phenotypes}

To study the inheritance of pisatin demethylation phenotypes, isolates of different phenotypes for pisatin demethylation, mating type and female fertility were mated. The results of random ascospore isolations of these crosses are given in Table 2.

$A$ cross between PDA $^{i}(T-2)$ and PDA $^{n}$ (T-219) field isolates resulted in some progeny that lacked demethylase activity altogether (cross 44 ). Twenty of 100 ascospores were of this PDAphenotype, indicating that the determinants of the parental demethylating phenotypes are nonallelic. Crosses between PDA - progeny of this cross or a subsequent cross and the PDA ${ }^{n}$ parent isolate (T-219) resulted in 1:1 segregation for the parental demethylating phenotypes (crosses 62 and 76), indicating that these strains differed at a single gene.

Crosses between the PDA ${ }^{i}$ parent isolate (T-2) of cross 44 and $\mathrm{PDA}^{-}$progeny of cross 44 (crosses 71 and 75 ) showed an approximate $2: 1: 2$ ratio for PDA $^{i}:$ PDA $^{n}:$ PDA $^{-}$. This segregation pattern indicated a more complex control of pisatin demethylating ability in isolate T-2. To gain further insight into the nature of this control, a PDA isolate from cross 75 (75-10) was backcrossed with the PDA- parent of cross 75 (44-100). This cross resulted in a segregation pattern of approximately $2: 1: 1$ for $\mathbf{P D A}^{i}: \mathbf{P D A}^{\mathrm{n}}: \mathbf{P D A}^{-}$(cross 77 ). This segregation ratio could be explained if isolate 75-10 contained positive alleles at two demethylase loci: an allele at one 
Table 2. Occurrence of pisatin demethylase phenotypes in random ascospore cultures

\begin{tabular}{|c|c|c|c|c|c|c|c|c|c|c|c|}
\hline \multirow{2}{*}{$\begin{array}{c}\text { Cross } \\
\text { no. }\end{array}$} & \multirow{2}{*}{$\begin{array}{l}\text { Parent } \\
\text { isolate* }\end{array}$} & \multirow{2}{*}{$\begin{array}{c}\text { Parent } \\
\text { phenotype }\end{array}$} & \multicolumn{3}{|c|}{$\begin{array}{r}\text { Inferred } \\
\text { genotypet }\end{array}$} & \multirow{2}{*}{$\begin{array}{c}\text { Progeny } \\
\text { germination } \\
(\%)\end{array}$} & \multicolumn{3}{|c|}{$\begin{array}{l}\text { Demethylase phenotype } \\
\text { (no. of ascospores) }\end{array}$} & \multirow{2}{*}{$\begin{array}{l}\text { Expected } \\
\text { ratio }\end{array}$} & \multirow[b]{2}{*}{$x^{2}$} \\
\hline & & & 1 & 2 & 3 & & PDA' $^{\prime}$ & PDA $^{n}$ & $\mathrm{PDA}^{-}$ & & \\
\hline 44 & $\begin{array}{l}T-219 \\
T-2\end{array}$ & $\begin{array}{l}\text { PDA }^{n} \\
\text { PDA }^{\prime}\end{array}$ & $\overline{+}$ & $\overline{+}$ & $\begin{array}{l}+ \\
-\end{array}$ & 93 & 48 & 32 & 20 & $4: 3: 1$ & $5 \cdot 39$ \\
\hline 62 & $\begin{array}{l}T-219 \\
44-64\end{array}$ & $\begin{array}{l}\text { PDA }^{n} \\
\text { PDA }^{-}\end{array}$ & - & - & $\begin{array}{l}+ \\
-\end{array}$ & 46 & 0 & 27 & 23 & $0: 1: 1$ & $0 \cdot 32$ \\
\hline 76 & $\begin{array}{l}T \cdot 219 \\
62-11\end{array}$ & $\begin{array}{l}\text { PDA }^{n} \\
\text { PDA }^{-}\end{array}$ & - & $\begin{array}{l}- \\
-\end{array}$ & $\begin{array}{l}+ \\
-\end{array}$ & 44 & 0 & 21 & 23 & $0: 1: 1$ & 0.09 \\
\hline 71 & $\begin{array}{l}44-82 \\
T \cdot 2\end{array}$ & $\begin{array}{l}\text { PDA }^{-} \\
\text {PDA' }^{\prime}\end{array}$ & $\overline{+}$ & $\overline{+}$ & - & 28 & 20 & 9 & 21 & $2: 1: 1$ & $7 \cdot 76 \ddagger$ \\
\hline 75 & $\begin{array}{l}44-100 \\
T \cdot 2\end{array}$ & $\begin{array}{l}\text { PDA }^{-} \\
\text {PDA }^{\prime}\end{array}$ & $\overline{+}$ & $\overline{+}$ & - & 38 & 36 & 16 & 34 & $2: 1: 1$ & $9 \cdot 82 \ddagger$ \\
\hline 77 & $\begin{array}{l}44-100 \\
75-10\end{array}$ & $\begin{array}{l}\text { PDA }^{-} \\
\text {PDA }^{1}\end{array}$ & - & $\overline{+}$ & - & 45 & 23 & 10 & 14 & $2: 1: 1$ & 0.70 \\
\hline 94 & $\begin{array}{l}44-100 \\
77-2-3\end{array}$ & $\begin{array}{l}\text { PDA } \\
\text { PDA' }^{\prime}\end{array}$ & $\overline{+}$ & - & $\begin{array}{ll}- \\
-\end{array}$ & 79 & 23 & 0 & 27 & $1: 0: 1$ & 0.32 \\
\hline 95 & $\begin{array}{l}77-2-8 \\
62-18\end{array}$ & $\begin{array}{l}\text { PDAn }^{n} \\
\text { PDA }^{n}\end{array}$ & - & $\begin{array}{l}+ \\
-\end{array}$ & $\overline{+}$ & 94 & 0 & 28 & 12 & $0: 3: 1$ & 0.53 \\
\hline 73 & $\begin{array}{l}T-219 \\
44-9\end{array}$ & $\begin{array}{l}\text { PDA }^{\mathbf{n}} \\
\text { PDA }^{n}\end{array}$ & - & $\overline{+}$ & $\begin{array}{l}+ \\
-\end{array}$ & 17 & 0 & 53 & 6 & $0: 3: 1$ & $6 \cdot 29 \ddagger$ \\
\hline 96 & $\begin{array}{l}77-2-5 \\
142-39\end{array}$ & $\begin{array}{l}\text { PDA }^{n} \\
\text { PDA }\end{array}$ & - & $\begin{array}{l}+ \\
-\end{array}$ & - & 81 & 0 & 19 & 21 & $0: 1: 1$ & $0 \cdot 10$ \\
\hline 99 & $\begin{array}{l}77-2-5 \\
95-16\end{array}$ & $\begin{array}{l}\text { PDA }^{n} \\
\text { PDA }^{-}\end{array}$ & $\begin{array}{l}- \\
-\end{array}$ & $\begin{array}{l}+ \\
-\end{array}$ & $\begin{array}{l}- \\
-\end{array}$ & 82 & 0 & 18 & 22 & $0: 1: 1$ & 0.40 \\
\hline 74 & $\begin{array}{l}44-100 \\
T-9\end{array}$ & $\begin{array}{l}\text { PDA }^{-} \\
\text {PDA' }^{\prime}\end{array}$ & & & & $>99$ & 6 & 22 & 22 & & \\
\hline
\end{tabular}

- Female parent listed first.

† Symbols refer to alleles at inferred pisatin demethylase loci, designated pda- $l$ (positive allele confers PDA' phenotype), pda-2 and pda-3 (positive alleles confer PDAn phenotype).

Rejected at $P=0.05$.

Table 3. Pisatin demethylase phenotypes in tetrads of crosses 77,94 , and 74

$\begin{array}{ccc}\text { Cross no. } & \begin{array}{c}\text { Segregation pattern } \\ \text { (PDA' }^{\prime}: \text { PDA }^{n}: \text { PDA }^{-} \text {) }\end{array} & \text { No. of tetrads } \\ 77 & 4: 0: 4 & 4 \\ & 4: 4: 0 & 4 \\ & 4: 2: 2 & 4 \\ 94 & 2: 0: 6 & 1 \\ 74 & 4: 0: 4 & 8 \\ & 8: 0: 0 & 1 \\ 440: 4 & 3\end{array}$

locus confering the $\mathrm{PDA}^{\mathrm{n}}$ phenotype, and an allele at a second locus, conferring an epistatic

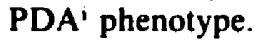

To test this hypothesis, tetrads from cross 77 were isolated and analysed for pisatin demethylation phenotype. The results (Table 3 ) are consistent with this hypothesis. The putative PDA loci segregated predominantly as parental ditype $(4: 0: 4)$ and implied non-parental ditype (4:4:0) or tetratype asci $(4: 2: 2)$. A single $2: 0: 6$ ascus was also found. This ratio may have arisen from a loss of one meiotic product followed by a reduplication of an existing sister ascospore, since FEM and MAT also segregated 2:6 for the parental phenotypes in this tetrad, whereas in all other tetrads segregation for these traits was $4: 4$. The possibility that this segregation pattern resulted from an error during isolation of the ascospores also cannot be excluded.

To test further whether isolate 75-10 contains two genes for pisatin demethylase activity, cultures derived from ascospores from a 4:4:0 tetrad of cross 77 (ascus 2) were further crossed 
with PDA- isolates. When a culture with the PDA' phenotype (77-2-3) from this ascus was crossed with a PDA- isolate, parental demethylase phenotypes segregated $1: 1$ in random ascospore isolations (cross 94 , Table 2). In addition, each of eight tetrads isolated from cross 94 segregated 4:4 for $\mathrm{PDA}^{\mathrm{i}}$ and $\mathrm{PDA}^{-}$ascospores (Table 3). Likewise, when a culture with the PDA $^{\mathbf{n}}$ phenotype from ascus 2, cross 77 (77-2-5) was crossed with PDA- isolate, parental demethylase phenotypes segregated $1: 1$ in random ascospore isolates (crosses 96 and 99, Table 2). These results are consistent with the interpretation that two pisatin demethylase genes exist in ascospore 75-10.

The PDA ${ }^{n}$ gene inferred from crosses 96 and 99 is apparently non-allelic to the PDAn gene from isolate T-219. When a cross between 77-2-8 (PDA ${ }^{n}$ derived from 75-10) and 62-18 (PDA ${ }^{n}$ derived from T-219) was analysed, an approximate 3:1 ratio of $\mathrm{PDA}^{n}: \mathrm{PDA}^{-}$was obtained in random ascospore progeny (cross 95 , Table 2). Similarly, a cross of the parental and progeny $\mathrm{PDA}^{n}$ isolates from cross 44 (cross 73 ) resulted in $\mathrm{PDA}^{-}$progeny, although the frequency in random ascospores was inconsistent with the $3: 1$ ratio expected of unlinked alleles. Regardless of considerations of linkage, these results support the idea that these isolates are sources of distinct genes, either or both of which confer the PDA ${ }^{n}$ phenotype.

In summary, it appears that three loci determine pisatin demethylating ability in the parents of cross 44. An allele at one locus (designated pda-3) present in isolate T-219 results in the PDA ${ }^{n}$ phenotype (crosses 62 and 76). Alleles at the other loci, present in ascospore 75-10, confer either the PDA ${ }^{i}$ phenotype ( $p d a-1$, cross 94 ) or the PDA $^{n}$ phenotype ( $p d a-2$, crosses 96 and 99 ). Since the high level of pisatin demethylase activity resulting from pda-1 masks the presence or absence of activity derived from pda-2 and pda-3, a 4:3:1 ratio of PDA $^{i}:$ PDA $^{n}:$ PDA $^{-}$phenotypes would be expected in cross 44 if all demethylase loci segregate independently. The observed frequency of demethylase phenotypes in this cross is not inconsistent with this ratio (Table 2).

Since active alleles at $p d a-I$ and $p d a-2$ must ultimately be derived from field isolate $T-2$, a ratio of $2: 1: 1$ is expected for PDA ${ }^{i}: P^{n} A^{n}: P^{-}$in crosses 71 and 75 . However, the observed frequencies for these phenotypes do not support this interpretation. In both crosses, a greater number of PDA - progeny was observed than expected. This result could be explained by the presence of a gene or genes which result in an epistatic PDA- phenotype. The existence of such genes in $N$. haematococca has been proposed (Tegtmeier \& VanEtten, 1982b), but attempts to demonstrate their presence directly have been unsuccessful to date (W. Cowling, personal communication). Also peculiar to crosses 71 and 75 is the fact that FEM segregated in $14: 35$ and $4: 55\left(\mathrm{FEM}^{+}: \mathrm{FEM}^{-}\right)$ratios respectively, and for cross 71 the $\mathrm{MAT}^{+}: \mathrm{MAT}^{-}$ratio was $37: 12$, whereas both traits segregated in $1: 1$ ratios in all other crosses. Ascospore germination was low $(<40 \%)$ in crosses 71 and 75 (Table 2), and events affecting viability of ascospores in these crosses may also influence segregation of the traits under consideration. A further indication that random ascospore data must be interpreted with caution was obtained in a cross between another $\mathrm{PDA}^{i}$ field isolate, T-9, and the $\mathrm{PDA}^{-}$isolate 44-100 (cross 74, Table 2). In random ascospore analysis only six of 50 progeny were of the parental PDA ${ }^{i}$ phenotype, despite the fact that segregation for MAT and FEM was as expected and germination of random ascospores was $>99 \%$. However, examination of asci indicated that $>90 \%$ contained four (or sometimes fewer) ascospores. Asci containing seven or eight ascospores rarely were seen, but those that were isolated segregated either 8:0 or 4:4 $\mathrm{PDA}^{\mathrm{i}}: \mathrm{PDA}^{-}$(Table 3).

\section{Linkage of pda-l and fem}

Recombination frequencies were determined in random ascospore progeny of three crosses where the segregation of PDA ${ }^{i}$ and FEM traits was consistent with control by the single genes $p d a-I$ and $f e m$ (crosses 44,77 and 94). In all crosses the PDA parent was of the FEM ${ }^{-}$, MAT $^{-}$ phenotype. Of these 196 progeny, only 31 were recombinants with respect to pda-l and fem (8 $\mathrm{PDA}^{i}, \mathrm{FEM}^{+}$progeny and $23 \mathrm{PDA}^{-}$or $\mathrm{PDA}^{n}$ progeny that were $\mathrm{FEM}^{-}$). In contrast, 91 of 196 were recombinants with respect to pda-l and MAT. These findings suggest that the genetic determinants of the inducible pisatin demethylase phenotype and female fertility are linked. Tetrad data from crosses 77 and 94 (excluding the anomalous $2: 6$ ascus in cross 77 ) also showed single gene control of FEM and PDA'. With respect to these traits, 18 parental ditype, no non- 
parental ditype, and two tetratype asci were observed, again demonstrating linkage between pda-l and fem. In contrast, MAT and PDA' showed nine parental ditype, seven non-parental ditype and four tetratype asci.

\section{DISCUSSION}

Field isolates of $N$. haematococca can display different phenotypes with respect to whole cell pisatin demethylase activity (VanEtten \& Matthews, 1984; VanEtten et al., 1980). Isolates having no detectable activity $\left(\mathrm{PDA}^{-}\right)$, only low activity $\left(\mathrm{PDA}^{\mathrm{n}}\right)$, or a high, substrate-induced level of pisatin demethylase activity (PDA') exist in nature. The results presented here with isolates T-2 and T-219 indicate that these pisatin demethylase phenotypes are distinct and are passed on to progeny as distinct phenotypes.

The results suggest that a pair of alleles at one locus (designated pda-l) determines the presence or absence of the PDA' phenotype. Alleles at two other loci ( $p d a-2$ and $p d a-3$ ) each can confer the PDA $^{n}$ phenotype. The apparent epistasis of the PDA $^{i}$ phenotype conferred by pda-I toward genes conferring the PDA ${ }^{n}$ phenotype is due to the inability to detect a small additional amount of pisatin demethylase activity in a high activity PDA ${ }^{i}$ background. Negative alleles at every locus result in PDA- individuals.

Linkage seems to occur between pda- 1 and the locus that confers the female fertile trait, fem. In random ascospores from three crosses, only approximately $16 \%$ recombination occurred between PDA $^{i}$ and the FEM ${ }^{-}$phenotypes conferred by $p d a-1$ and fem. The frequency of recombination for these traits in tetrads was $5 \%$ (two tetratype asci of 20 examined). An attempt to support the idea of linkage by crossing $\mathrm{PDA}^{\prime}, \mathrm{FEM}^{+}$recombinants with $\mathrm{PDA}^{-}, \mathrm{FEM}^{-}$ strains was unsuccessful due to the low fertility of the PDA', FEM ${ }^{+}$strains used. Low fertility, as expressed by few or poorly formed perithecia and poor ascospore germination, is a problem with many isolates of $N$. haematococca regardless of pisatin demethylase phenotype.

Low fertility, however, was not the cause of aberrant segregation for pisatin demethylating ability in a cross involving field isolate T-9 (cross 74). One interpretation of the noted low frequency of PDA $^{i}$ progeny among random ascospores in this cross is that PDA progeny are preferentially aborted in asci.

Ascospore 'killer' or 'abortion' factors have been extensively described in Neurospora (e.g. Turner \& Perkins, 1979) and in lesser detail for some fungal plant pathogens, including Hypomyces ipomoeae ( $N$. haematococca MP II) (Dimock, 1937), Venturia inaequalis (Yoder et al., 1982), and Fusarium moniliforme (Gibberella fujikuroi) (Kathariou \& Spieth, 1982). These factors cause selective loss of half the meiotic products of most asci, with loss often under simple, nuclear control (Kathariou \& Spieth, 1982; Turner \& Perkins, 1979). Often incomplete penetrance of the killer phenotype allows for a low percentage of eight-spored asci (Kathariou \& Spieth, 1982). Ascus formation in cross 74 appears similar to these killer phenotypes. Linkage of genes for killer and PDA $^{i}$ phenotypes could account for the low frequency of PDA $^{i}$ random ascospores in cross 74 when compared to that of tetrads. However, other phenomena such as reciprocal translocations in field isolates could conceivably also explain the data of cross 74 . Further study is required in order to understand these results.

The nature of the gene products of $p d a-I, p d a-2$ or $p d a-3$ is not known. Previous evidence has shown that pisatin demethylation in field isolate T-9 of Nectria haematococca is catalysed by a membrane-associated cytochrome P-450 monooxygenase (Desjardins et al., 1984; Matthews \& VanEtten, 1983). One simple interpretation of the genetic data is that each locus represents a distinct structural gene for a pisatin demethylase enzyme. Distinct isoenzymic forms of cytochrome P-450 enzymes are known to exist in mammals (Guengerich et al., 1982; Lang et al., 1981 ; Negishi \& Nebert, 1979; Sato et al., 1982; Tukey et al., 1982). However, gene products governing cofactors, enzyme regulation, or substrate transport might also explain our results. Likewise it is unclear whether the difference between PDA $^{i}$ and $\mathbf{P D A}^{n}$ individuals results from structurally different enzymes with a similar function, or if the difference is more of a regulatory nature. An effort is now being made to correlate genes conferring pisatin demethylase activity with specific protein products. 
Whether other genes for pisatin demethylation exist remains to be determined. Although the biochemical mechanisms resulting in the PDA $^{i}$ phenotype are unknown, recent data show a correlation between the $\mathrm{PDA}^{\mathrm{i}}$ phenotype and extreme tolerance to pisatin as well as virulence toward Pisum sativum. These results are discussed in an accompanying paper (Kistler \& VanEtten, 1984).

The authors wish to thank P. S. Matthews for technical assistance, D. E. Matthews and A. E. Desjardins for critical evaluation and B. Mosher for help in preparation of this manuscript. This research was supported in part by Rockefeller Foundation grant RF 81042-26 and USDA Competitive Research Grants Program grant 80CRCR-1-0477.

\section{REF ERENCES}

Cruickshunx, I. A. M. (1980). Defenses triggered by the invader: Chemical defenses. In Plant Disease: An Advanced Treatise, vol. V, pp. 247-267, Edited by J. G. Horsfall \& E. B. Cowling, New York \& London: Academic Press.

Defaco, G., KerN, H. \&edlar, L. (1983). Genetic analysis of tomatine insensitivity, sterol content and pathogenicity for green tomato fruits in mutants of Fusarium solani. Physiological Plant Pathology 22, 39-43.

Desuadins, A. E., Matthews, D. E. \& Vanetten, H. D. (1984). Solubilization and reconstitution of pisatin demethylase, a cytochrome P-450 from the pathogenic fungus Nectria haematococca. Plant Physiology (in the Press).

Drmock, A. W. (1937). Hybridization studies on a zincinduced variant of Hypomyces ipomoeae. Mycologia 29, 273-285.

Guengenich, F. P., Dannan, G. A., Wright, S. T., Martin, M. V. \& Kamansxy, L. S. (1982). Purification and characterization of liver microsomal cytochromes P-450: Electrophoretic, spectral, catalytic, and immunochemical properties and inducibility of eight isozymes isolated from rats treated with phenobarbital or $\beta$-Naphthoflavone. Biochemistry 21, $6019-6030$.

Holenstein, J. \& Defaco, G. (1983). Inheritance of naphthazarin production and pathogenicity to pea in Nectria haematococca. Journal of Experimental Botany 34, 927-935.

Kathukiou, S. \& Spieth, P. T. (1982). Spore killer polymorphism in Fusarium moniliforme. Genetics 102, 19-24.

KISTLER, H. C. (1983). Phytoalexin metabolism and implications for phytoalexin tolerance and virulence in two plant pathogenic fungi. PhD thesis, Cornell University, Ithaca, NY, USA.

KLSTler, H. C. \& VAnEtien, H. D. (1984). Regulation of pisatin demethylation in Nectria haematococca and its influence on pisatin tolerance and virulence. Journal of General Microbiology 130, 26052613.

Lano, M. A., Gielen, J. E. \& Nebert, D. W. (1981). Genetic evidence for many unique liver microsomal $\mathrm{P}-450$-mediated monooxygenase activities in heterogeneic stock mice. Journal of Biological Chemistry 256. 12068-12075.

Matthews, D. E. \& VanEtren, H. D. (1983). Detoxification of the phytoalexin pisatin by a fungal cytochrome P-450. Archives of Biochemistry and Biophysics 224, 494-505.
Negishi, M. Nebert, D. W. (1979). Structural gene products of the Ah locus. Journal of Biological Chemistry 254, 11015-11023.

Perrin, D. R. Botromley, W. (1962). Studies on phytoalexins. V. The structure of pisatin from Pisum sativum L. Joumal of the American Chemical Society 84, 1919-1922.

Sato, R., Aoyaun, T. Imal, Y. (1982). Multiple forms of cytochrome $P-450$ from liver microsomes of drug untreated rabbits: Purification and characterization. In Oxygenases and Oxygen Metabolism, pp. 321-332. Edited by M. Nozaki. New York: Academic Press.

Stevens, R. B. (editor) (1974). Mycology Handbook. Seattle \& London: University of Washington Press.

Tegtmeier, K. J. VanEtten, H. D. (1982a). Genetic studies on selected traits of Nectria haematococca. Phytopathology 72, 604-607.

Tequmeier, K. J. \& VanEtTEN, H. D. (1982b). The role of pisatin tolerance and degradation in the virulence of Nectria haematococca on peas: A genetic analysis. Phytopathology 72, 608-612.

Tuxey, R. H., Neolshi, M. \& Nebert, D. W. (1982). Quantitation of hepatic cytochrome $P_{1}-450$ mRNA with the use of a cloned DNA probe. Molecular Pharmacology 22, 779-786.

TuRner, B. C. \& Pekrins, D. D. (1979). Spore killer, a chromosomal factor in Neurospora that kills meiotic products not containing it. Genetics $93,587-606$.

VANETTEN, H. D. (1973). Differential sensitivity of fungi to pisatin and to phaseolin. Phytopathology 63, 1477-1482.

VANETTEN, H. D. (1978). Identification of additional habitats of Nectria haematococca mating population VI. Phytopathology 68, 1552-1556.

VAnEtTEN, H. D. (1982). Phytoalexin detoxification by monooxygenases and its importance for pathogenicity. In Plant Infection: The Physiological and Biochemical Basis, pp. 315-327. Edited by Y. Asada, W. R. Bushnell, S. Ouchi \& C. P. Vance. Berlin: Japan Sci. Soc. Press, Tokyo/Springer-Verlag.

VAnEtten, H. D. \& Matthews, P. S. (1984). Naturally-occurring variation in the induction of pisatin demethylating ability in Nectria haematococca mating population V1. Physiological Plant Pathology (in the Press).

Vanetten, H. D., Pueppee, S. G. Kelsey, T. C. (1975). 3,6a-Dihydroxy-8,9-methylenedioxypterocarpan as a metabolite of pisatin produced by Fusarium solani f. sp. pisi. Phytochemistry 14, 11031105. 
VanEtTen, H. D., Matthews, P. S., Tegtmeier, K. J., Dibtent, M. F. \& SteIN, J. I. (1980). The association of pisatin tolerance and demethylation with virulence on pea in Nectria haematococca. Physiological Plant Pathology 16, 257-268.

VanEtten, H. D., Matthews, D. E. \& SMrth, D. A. (1982). Metabolism of Phytoalexins. In Phytoalexins, pp. 181-217. Edited by J. A. Bailey \& J. W. Mansfield. Glasgow \& London: Blackie.

Yoder, K. S., Klos, E. J., Nowacta, H. Bielenin, A. (1982). Inheritance of an ascospore abortion factor in Venturia inaegualis. Canadian Journal of Botany 60, 2105-2111. 